\title{
Strength Increasing Of Ultrafine Unsized Tailing Back-filling Materials
}

\author{
Chen chao ${ }^{1, a}$ Li Hongbao $^{1}$ \\ ${ }^{1}$ College of Mining Engineering, North China university of technology,Tangshan, Hebei, \\ 063009, China \\ a13931501518@163.com
}

Keywords: ultrafine unsized tailing, back-filling, strength increasing

Abstract. This paper adopts physical experiment method to design uniform experiment on the basis of ultrafine unsized tailing in allusion to the problem of ultrafine unsized tailing back-filling. In this paper, the relationship between the strength of filling material and the ingredients-concentration-ratio of ultrafine unsized tailing backfilling materials is analyzed. The principle of mechanical property $\&$ it's change of ultrafine unsized tailing back-filling materials is reveal.

\section{Introduction}

The crystallization grain size of iron ore in the eastern area of Hebei is relatively small. The excessive smashing of iron ore is necessary to improve resource recovery, which increases greatly ultrafine particles in the tailings. The increasing greatly of ultrafine unsized particles is adverse effect to the unsized back-filling mining method and lead to excessive consumption of cementing material, reduction in unsized tailing back-filling materials strength and unsteadiness pipeline transport parameter. And then, the applying of ultrafine unsized tailing back-filling mining method is getting harder because cost increase, unsteadiness quality and depravation of back-filling process reliability.

\section{Experimental program}

The Diamond No. 325 Portland cement and whole tailings were used as the cementing material and aggregates. A total of three factors, such as cement-sand ratio, mass concentration and curing age, were selected as the experimental data. A total of 36 groups of experiments were conducted, and 6 test blocks were made in each group. The specific parameters were shown in Table 1.

\section{Strength test}

Measurement of uniaxial compressive strength of test block was conducted by WAW-2000 press in the form of axial compression. There were three test blocks in each group, the average value of that was the uniaxial compressive strength, and the results were shown in Table 1.

\section{Strength analysis of superfine whole tailings-cemented filling}

Effect of mass concentration on strength of superfine whole tailings-cemented filling Effect of mass concentration on filling strength at the same curing age

Based on the analysis of the test results, the higher concentration of the slurry meant the greater of the uniaxial compressive strength of the whole tailings-cemented filling when the cement-sand ratio of the cemented slurry remained the same standard. The relationship was shown in Fig.1. 

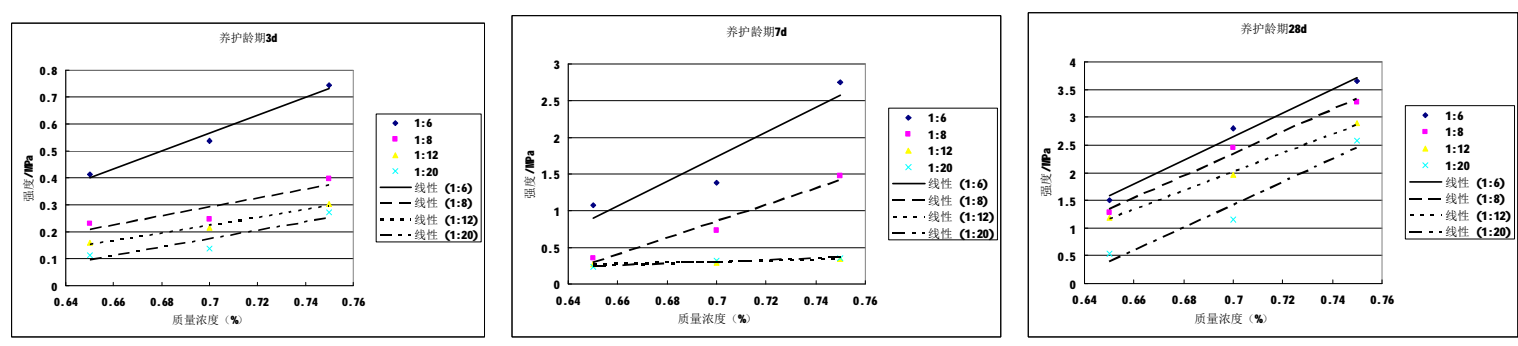

a.Curing age of three days b.Curing age of seven days c.Curing age of twenty-eight days

Fig. 1 The curve of compressive strength with mass concentration at different curing ages

Table1 The results of strength test of whole tailings-cemented filling

\begin{tabular}{|c|c|c|c|c|}
\hline ID & $\begin{array}{c}\text { mass } \\
\text { concentration }\end{array}$ & $\begin{array}{l}\text { cement-sand } \\
\text { ratio }\end{array}$ & curing age & strength ( $\mathrm{MPa})$ \\
\hline A11 & $65 \%$ & $1: 6$ & $3 d$ & 0.413 \\
\hline A12 & $65 \%$ & $1: 6$ & $7 \mathrm{~d}$ & 1.08 \\
\hline A13 & $65 \%$ & $1: 6$ & $28 \mathrm{~d}$ & 1.5 \\
\hline $\mathrm{A} 21$ & $65 \%$ & $1: 8$ & $3 d$ & 0.232 \\
\hline A22 & $65 \%$ & $1: 8$ & $7 \mathrm{~d}$ & 0.36 \\
\hline A23 & $65 \%$ & $1: 8$ & $28 \mathrm{~d}$ & 1.288 \\
\hline A31 & $65 \%$ & $1: 12$ & $3 d$ & 0.158 \\
\hline A32 & $65 \%$ & $1: 12$ & $7 d$ & 0.276 \\
\hline A33 & $65 \%$ & $1: 12$ & $28 \mathrm{~d}$ & 1.19 \\
\hline A41 & $65 \%$ & $1: 20$ & $3 d$ & 0.114 \\
\hline A42 & $65 \%$ & $1: 20$ & $7 d$ & 0.241 \\
\hline A43 & $65 \%$ & $1: 20$ & $28 \mathrm{~d}$ & 0.53 \\
\hline B11 & $70 \%$ & $1: 6$ & $3 d$ & 0.538 \\
\hline B12 & $70 \%$ & $1: 6$ & $7 d$ & 1.382 \\
\hline B13 & $70 \%$ & $1: 6$ & $28 \mathrm{~d}$ & 2.453 \\
\hline $\mathrm{B} 21$ & $70 \%$ & $1: 8$ & $3 d$ & 0.246 \\
\hline B22 & $70 \%$ & $1: 8$ & $7 d$ & 0.732 \\
\hline B23 & $70 \%$ & $1: 8$ & $28 \mathrm{~d}$ & 2.799 \\
\hline B31 & $70 \%$ & $1: 12$ & $3 d$ & 0.251 \\
\hline B32 & $70 \%$ & $1: 12$ & $7 d$ & 0.293 \\
\hline B33 & $70 \%$ & $1: 12$ & $28 \mathrm{~d}$ & 1.968 \\
\hline B41 & $70 \%$ & $1: 20$ & $3 d$ & 0.139 \\
\hline B42 & $70 \%$ & $1: 20$ & $7 d$ & 0.319 \\
\hline B43 & $70 \%$ & $1: 20$ & $28 \mathrm{~d}$ & 1.155 \\
\hline C11 & $75 \%$ & $1: 6$ & $3 d$ & 0.745 \\
\hline C12 & $75 \%$ & $1: 6$ & $7 d$ & 2.753 \\
\hline C13 & $75 \%$ & $1: 6$ & $28 d$ & 3.646 \\
\hline $\mathrm{C} 21$ & $75 \%$ & $1: 8$ & $3 d$ & 0.397 \\
\hline C22 & $75 \%$ & $1: 8$ & $7 d$ & 1.482 \\
\hline C23 & $75 \%$ & $1: 8$ & $28 \mathrm{~d}$ & 3.274 \\
\hline C31 & $75 \%$ & $1: 12$ & $3 d$ & 0.303 \\
\hline C32 & $75 \%$ & $1: 12$ & $7 d$ & 0.346 \\
\hline C33 & $75 \%$ & $1: 12$ & $28 \mathrm{~d}$ & 2.888 \\
\hline $\mathrm{C} 41$ & $75 \%$ & $1: 20$ & $3 d$ & 0.271 \\
\hline $\mathrm{C} 42$ & $75 \%$ & $1: 20$ & $7 d$ & 0.359 \\
\hline C43 & $75 \%$ & $1: 20$ & $28 \mathrm{~d}$ & 2.573 \\
\hline
\end{tabular}




\section{Effect of mass concentration on filling strength at the same cement-sand ratio}

Based on the influence of mass concentration on the strength of the whole tailings-cemented filling, a suitable cement-sand ratio could be chosen when the cement-sand ratio remained the same standard. The relationship was shown in Fig.2.
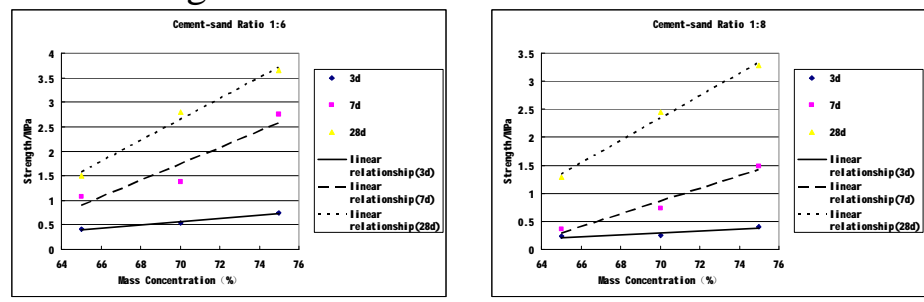

a.1:6 Cement-sand ratio of 1:6

b.1:8 Cement-sand ratio of $1: 8$
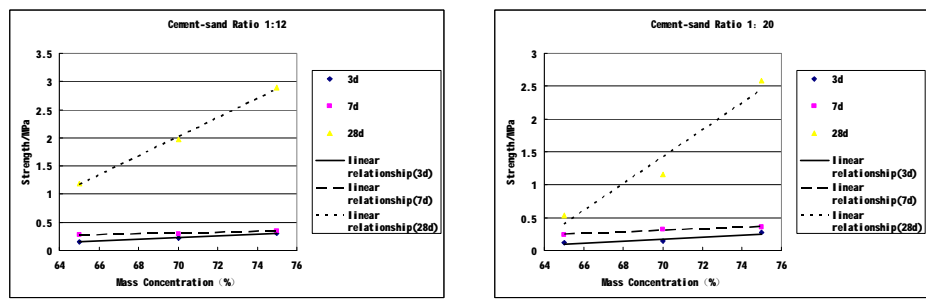

c.1:12 Cement-sand ratio of 1:12

d.1:20 Cement-sand ratio of 1:20

Fig.2 The curve of compressive strength with mass concentration at different curing ages and same cement-sand ratio

Effect of cement-sand ratio on strength of superfine whole tailings-cemented filling

Effect of cement-sand ratio on filling strength at the same curing age

The higher cement-sand ratio meant the greater the compressive strength of the filling, when other conditions remained unchanged,. The impact of cement-sand ratio on the strength of the filling was shown in Fig.3.

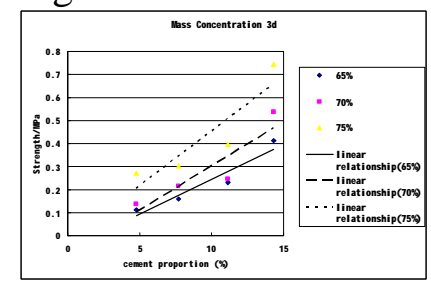

a. Curing age of three days

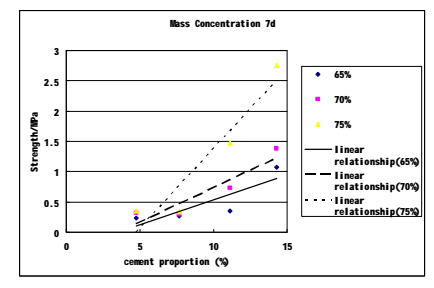

b.Curing age of seven days

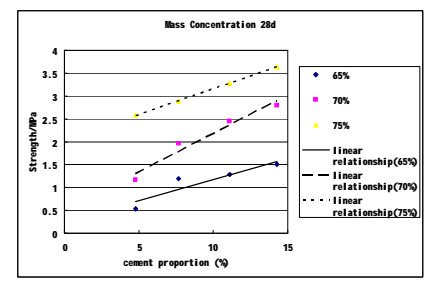

c.Curing age of twenty-eight days

Fig. 3 The curve of compressive strength with cement-sand ratio at different mass concentrations and same curing age

\section{Effect of cement-sand ratio on filling strength at the same mass concentration}

The cement-sand ratio was an important factor in determining the strength of the filling. The study on the variation law of the filling strength changed with the cement-sand ratio could provide the basis for choosing the reasonable cement-sand ratio and avoid the high cost of filling caused by the high cement-sand ratio. The relationship of cement-sand ratio and strength were shown in Fig.4.

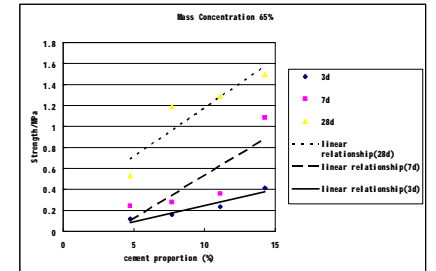

a.65\% Mass concentration of $65 \%$

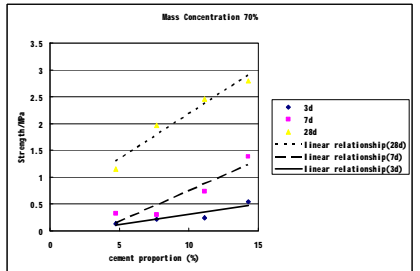

b.70\% Mass concentration of $70 \%$

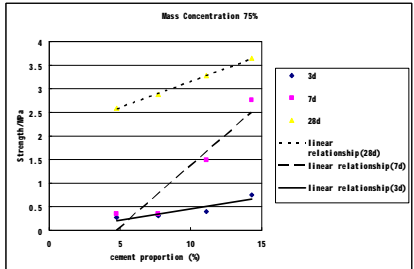

c. $75 \%$ Mass concentration of $75 \%$

Fig.4 The curve of compressive strength with cement-sand ratio at different curing ages and same mass concentration 


\section{Effect of curing age on filling bodies strength}

The effect of the curing age on the strength is shown in Figure5, which can be seen from the graphs in Figure 5, when the mass concentration is constant, the intensity of each mortar increases with the growth of curing age. The strength increases slowly with the duration of curing age is 3 days and 7 days, and the strength increases rapidly when the curing age is 28 days, and the intensity of the increase was higher than that of 3 days and 7 days.
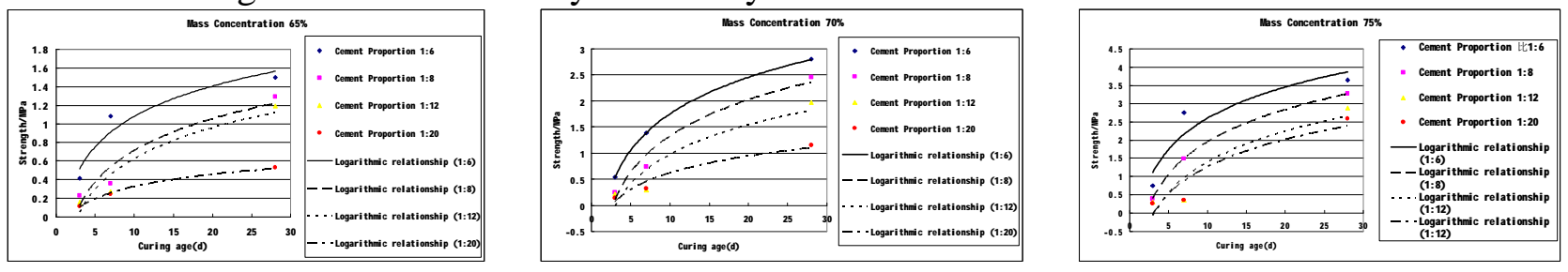

Fig.5 Intensity versus age of conservation

\section{Conclusions}

Using SPSS software, multivariate regression analysis was performed on the strength growth law of super-fine total tailings filling body, the results are as follows:

$$
\mathrm{y}=-7.516+8.635 x_{1}+0.069 x_{2}+9.721 x_{3}
$$

where $x_{1}$ is the gray sand ratio, $x_{2}$ is the curing age $(/ \mathrm{d})$ and $x_{3}$ is the concentration $(/ \%)$.

Sig $=0.000<0.05, R^{2}$ is 0.824 and the correlation is good.Through the multivariate regression analysis of the experimental data, it can be seen that the most important factor affected the strength of the filling bodies is the concentration of the slurry, the partial correlation coefficient is the largest. When design of cemented filling with the back-filling, we should first consider how to improve the slurry concentration; Secondly, the sand body of the filling body also has a greater impact on the strength, but it will be greatly increase the filling costs by increasing the amount of cement to improve the strength of the whole tail filling.

\section{Acknowledgements}

This work was financially supported by the Hebei Province Department of Education(ZD2015020), and

supported by the Graduate Student Innovation Fund of Hebei province(CXZZBS2017125).

\section{References}

[1] Huang Zhiwei, Zhang Bingxu. Research on new technology of whole tailings-classified backfilling[J]. Metal Mine, 2004(06):65-67.

[2] Xie Ying. Filling process and application prospect of full tailings[J]. Mining Technology, 2001(2):46-47,52.

[3] Li Dongqing. Research and application of metal mining technology in China[J]. Mining Technlogy, 2001(2):16-19,52.

[4] Gao Qian, Nan Shiqing, Sun Aizhi. Experimental study on the development of new filling material for superfine full tailings[C]. China nonferrous metals society mining committee. Proceedings of the 5th China filling mining technology and equipment conference. Hefei city, 2011:54-57. 